\title{
SHARIA HOSPITAL AS AN ADDED VALUE: A SYSTEMATIC REVIEW
}

\author{
Moh. Abdurrokhman'), Wachyu Sulistiadi²) \\ 1)Department of Policy and Health Administration, \\ Faculty of Public Health, Universitas Indonesia \\ ${ }^{2)}$ Masters Program in Public Health, \\ Faculty of Public Health, Universitas Indonesia
}

\begin{abstract}
Background: Sharia hospital is a hospital that provides health services in accordance with Sharia principle. According to framework Sharia based quality management system, the application of Sharia standard in the hospital management system may increase the quality of health care and improve patient satisfaction. This study aimed to review systematically Sharia hospital as an added value.

Subjects and Method: A systematic review was conducted by searching published articles from databases, including Google scholar, PubMed, Scopus, and ProQuest. The keywords were "hospital compliant Sharia", "patient satisfaction", "Sharia hospital", and "Islamic hospital". The inclusion criteria of this study were English, full text, and open access journal. The articles were reviewed using PRISMA flow diagram.

Results: Two studies from Malaysia reported the Sharia hospital principle was associated with patient satisfaction. Patient satisfaction related to factors including the availability of the facility for praying, and attitude of health workers in providing health services. Studies in Iran reported that care delivered by same-sex health worker also affected the satisfaction of female patients.
\end{abstract}

Conclusion: The application of Sharia principle in hospitals influences patient satisfaction.

Keywords: Sharia hospital, patient satisfaction

\section{Correspondence:}

Moh. Abdurrokhman, Department of Policy and Health Administration, Faculty of Public Health, Universitas Indonesia, Email: moh.abdurrokhman@ui.ac.id/dr.abdur@gmail.com. Mobile: 08562828985 .

\section{BACKGROUND}

In Islam, the purpose of human creation is to worship Allah SWT so that all activities in the life of a Muslim are to be obedient, submissive and worship. A Muslim must apply the principles of sharia in all aspects of his/her life so that all activities can be worth worship.

Sharia is an Islamic law that regulates all aspects of human life related to worship, muamalah, munakahah, and jinayah. Concern of Muslims towards the application of sharia principles in all aspects of life is increasing (Shariff and Mohtar, 2016).
Maqashid sharia means the purpose of law. Maqashid, from the word qashada which means purpose. Maqashid in terminology means the meanings and wisdoms and the like that God wants in every Shari'a, both general and specific, to ensure the benefit of His servants. Syatibi divided the benefits into three consecutive degrees according to the level of human needs, namely: dharuriyyah, hajjiyyah, and tahsiniyyah.

Dharuriyyah holds the highest degree of maslahah because humans cannot live without it. Maslahah dharuriyyah is done by 
preserving religion, self, religion, wealth, and reason. Maslahah after dharuriyyah is maslahah hajjiyyah. Hajjiyyah maslahah is a problem that is easy to prevent people from difficulties and distresses. Lastly is Maslahah tahsiniyyah. Maslahah tahsiniyyah is a complement or a refinement of the two previous maqasid, including customs and noble traditions (Zatadini and Syamsuri, 2018).

According to the Maqashid sharia and based on the Maslahah dharuriyyah, humans have 5 basic needs which consist of guarding religion (hifz ad-din), guarding of the soul (hifz an-nafs), guarding of reason (hifz al'aql), guarding offspring (hifz an- nasb) and safeguarding property (hifz al-mal) (Zakaria, 2014). These safeguards are the basis for the application of Islamic maqashid in hospitals.

Sharia hospital is a hospital that provides health services in accordance with sharia principles or in other words applying maqashid sharia in hospital governance. The characteristics of sharia hospitals that distinguish them from other hospitals are understanding related to the basic principles of sharia; understanding of the principles of halal and haram; understanding of the muamalat principle; the application of the concept of quality in Islam; and upholding Islamic values in hospital organizations.

These components are translated into operational management and services in the standard book. Some of these characteristics are 1) The presence of a sharia supervisory board appointed to oversee hospital operations; 2) Hospital by Laws covering sharia aspects; 3)The hospital's vision and mission explicitly state its Islamic goals; 4)Running sharia contracts with staff, patients, logistics providers, financial institutions and others; 5) HR Management applies sharia principles; Accounting and financial management applies sharia principles; 6) Providing physical facilities and facilitating patients, employees, and visitors to worship; 7) Providing spiritual guidance for patients and spiritual accompaniment for terminal sick patients; Ensure halal food, nutritional therapy, clean and safe; 8) In this Hospital, the services by officers of the same gender as patients and provide treatment rooms according to gender; 9) Prevention and control of infections using the principle of Thoharoh; 10) Hold religious training for all employees; Handling of complaints and disputes is settled according to sharia; 11) Providing Islamic reproductive health services; and 12) Hospitals pay zakat to help patients in need (Ismail et al., 2018).

SIRIM (Standard and Industrial Research Institute of Malaysia), the company appointed by the Malaysian standards department to develop, accredit and certify standards, has developed a sharia quality management system in general (MS 1900: 2014) which provides guidance for all organizations wishing to implement sharia-based quality management systems (Shariff and Mohtar, 2016). 


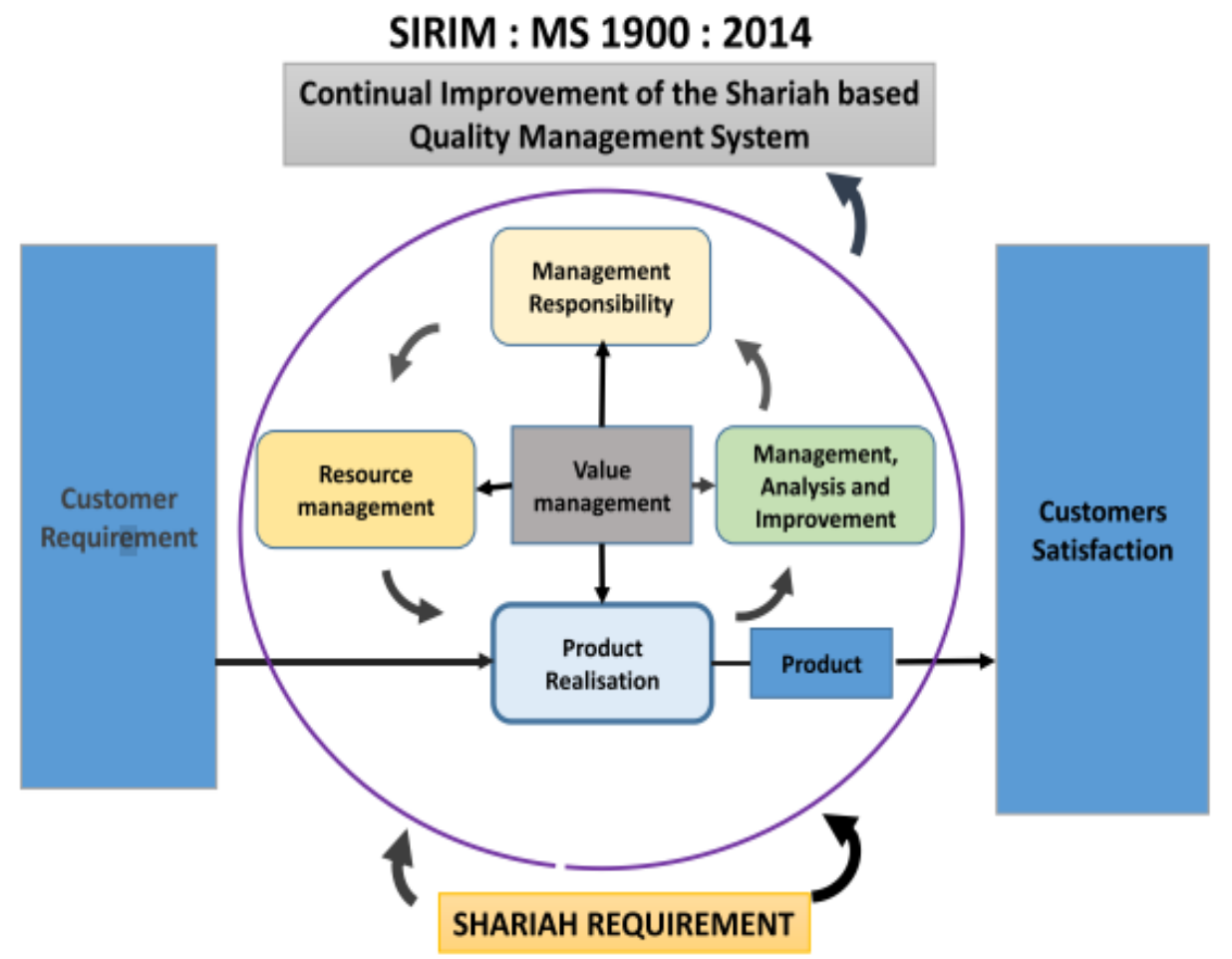

Figure 1 : Model of a Shari'ah based Quality Management System (Source: SIRIM MS 1900:2014. )

The Indonesian Islamic Health Efforts Council (MUKISI), in 2015, issued hospital service standards based on sharia principles, which complement national hospital accreditation standards. The standard was later stated by the National Sharia Council of the Indonesian Ulema Council (DSN-MUI) in 2016. In 2017 the second sharia hospital standard was published (Ismail et al., 2018)

One indicator of quality health care is the level of patient satisfaction. Based on SIRIM's Shariah based quality management system framework, the application of Sharia standards in the quality management system has an outcome in the form of customer satisfaction. The application of framework in hospitals is expected to increase patient satisfaction (Shariff and Mohtar, 2016).

Patient satisfaction is an indicator of the quality of health services. The higher the level of patient satisfaction, the more likely the patient is to choose health services, the greater the desire to return to a particular hospital or for re-control to a doctor or certain therapies.

There are many understandings regarding patient satisfaction. In general, this understanding has the characteristics according to the reference used (marketing and health).

First, satisfaction is an emotional or affective evaluation of services based on cognitive processes formed by expectations. Secondly, satisfaction is the compatibility between expectations and actual experience with health services (Batbaatar et al., 2015). One factor that influences patient satisfaction is religious factors. Patients who were invited to discuss religion or spiritual matters had a higher satisfaction than patients who were not invited to discuss religion or beliefs (Williams et al., 2011). The purpose of this study is to find out whether the application of maqashid syariah in hospitals has an influence on patient satisfaction. 


\section{SUBJECTS AND METHOD}

\section{Study Design}

Search for articles were done systematically through Google Scholar, Pubmed, Scopus and Proquest. Keywords used in the search were sharia compliant hospital, patient satisfaction, sharia hospital, Islamic hospital.

\section{Inclusion and Exclusion Criteria}

The inclusion criteria used were English language articles, full text and open access journals. Exclusion criteria were articles that were not in English, not full text, and not open access journals. Articles found were reviewed by using the PRISMA diagram.

\section{Study Variables}

The dependent variable in this study was patient satisfaction. The independent variable in this study was the sharia hospital standard.

\section{RESULTS}

From the search results, there were 41 articles with article duplication of 8 articles so there were 33 articles which were further filtered. From 33 articles, 3 articles were obtained which were in line with the study objectives. Two articles were studied in Malaysia and 1 studied article in Iran. Two studies in Malaysia directly mentioned sharia hospitals. While study in Iran did not mention sharia hospitals directly but has topics on the same gender health care delivery in accordance with sharia maqashid.

Rahman et al. (2018) conducted a study related to groups of factors that influence tourist loyalty to Islamic hospital services in Malaysia. The group of factors studied were sharia facilities, the quality of Islamic medical services provided by doctors and nurses. The group of factors that influence the satisfaction of Muslim tourists was the sharia facilities provided by hospitals and the quality of Islamic medical services provided by doctors.
Sharia facilities that affect patient satisfaction were the availability of comfortable places of worship; availability of suitable Shariah toilets; the provision of health services by the same gender as the patient and the availability of halal food for Muslim patients. The second group of factors that influence patient satisfaction were the quality of Islamic medical services provided by doctors. This included providing information on the use of vaccines originating from pigs; doctors clarified if they were not sure about the Islamic protocol; the use of halal medicines; respect and value patients' trust and privacy.

The quality of Islamic medical services provided by nurses did not affect tourist satisfaction. The quality of Islamic medical services provided by nurses consisted of cleaning the body parts affected by blood or urine so that patients can worship; nurses respect the religion and beliefs of patients; nurses were very sympathetic towards Muslim patients; and nurses try to provide privacy and a quiet environment when Muslim patients do the worship (Rahman et al., 2018).

Article written by Zailani et al. (2016) showed the factors that influence satisfaction of Muslim health tourists in Malaysia. There were three groups of factors examined namely the doctor's halal behavior, nurses' halal Behavior and hospital's halal behavior.

Based on this study, there were two groups of factors that influence the satisfaction of Muslim tourists. The two groups of factors were the halal behavior of doctors and hospitals.

Doctor's halal behavior consisted of several variables, namely providing information about the use of vaccines originating from pigs; the doctor facilitates the patient to keep practicing worship in the hospital; doctors made clarifications from Muslim patients when they were not sure about Islamic protocols; the doctor recommend handling 
the body in accordance with the patient's cultural and religious values; examination of female patients accompanied by other women; doctors discuss with patients regarding the contents of illicit drugs; doctors have a sense of moral responsibility to disclose the source of non-halal drug content and doctors chose halal medicines in practice.

While the hospital's halal behavior was indicated by several indicators including the hospital guaranteeing halal food, the hospital provided health personnels who have the same gender as the patient; the provision of blood transfusions from non-Muslim donors must obtain the consent of the patient or family and the hospital provided a satisfactory worship infrastructure. Worship facilities in the form of the availability of space for prayer, the availability of prayer rugs and the Al-Qur'an.

Whereas nurses' halal behavior consisted of cleansing parts of the body affected by blood, body fluids, urine or feces so that patients can worship; nurses respect the values and principles of Islam; nurses tried to provide privacy and a quiet environment when worshiping; and the patient valued the religious belief of the patient as having no effect on patient satisfaction (Zailani et al., 2016)

Study conducted in Iran in 2011 on same gender health care delivery in female patients stated that most respondents preferred to be provided health services by officers of the same gender. They did not approve some of the services provided by male officers such as those provided by male doctors especially those with family relationships; care, cleaning services, help to change positions and help with daily activities and the transfer process by male officers; urethral catheter placement and intramuscular injection; examination by male medical students; the presence of foreigners, male relatives and male officers during the inspection process; absence of body cover when laboratory or radiological examination.

They were very pleased with the separation of treatment rooms and the separation of bathrooms for men and women and the existence of body cover during a medical examination (Dargahi, 2011).

\section{DISCUSSIONS}

Variables in the study, according to the 1.438 Syariah hospital certification standards, most of them belong into the category of religious safeguards (hifz ad-din). In the sharia standard, facility management stated that the hospital applies standardization of facilities according to sharia principles, among others, was a ward arrangement according to gender, arrangement and maintenance of bathrooms according to sharia principles and provision of adequate worship facilities and management of halal kitchen according to sharia principles (MUKISI, 2017).

In the chapter on religious safeguards (hifz ad-din) the sharia standard of patient services stated that hospitals must ensure that all food and drinks served to patients have a MUI halal certificate.

The hospital must also maintain the patient's gender, apply patient inspection procedures according to gender and perform catheter placement procedures according to gender. Medicines used in hospitals should not contain forbidden substances. If using drugs containing substances that were forbidden, the hospital must make sharia informed consent (MUKISI, 2017).

From the three studies above, the application of sharia hospital standards directly affected patient satisfaction. From two studies in Malaysia, using structural equation modeling can show several groups of factors supporting patient satisfaction. While a study in Iran suggested that the majority of female patients agree with the 
application of services in accordance with Islamic principles.

The application of sharia principles in health services especially hospitals is an additional value that can increase patient satisfaction. The most dominant factor influencing patient satisfaction is the hospital's halal behavior and the availability of facilities that support patients to worship.

\section{REFERENCES}

Batbaatar E et al (2015). Conceptualisation of patient satisfaction: A systematic narrative literature review, Perspectives in Public Health, 243-250.

Dargahi H (2011). The Implementation of the Sharia Law in Medical Practice: A Balance between Medical Ethics and Patients Rights, Journal of medical ethics and history of medicine. Tehran University of Medical Sciences, 4: 7

Ismail SA et al. (2018). Journey to Shariah Hospital:An Indonesian Experience, International Journal of Human and Health Sciences (IJHHS), 2(2), p. 55.

MUKISI (2017). Standar \& Instrumen Sertifikasi Rumah Sakit Syariah Versi 1438 (Sharia Hospital Certification Standards \& Instruments Version 1438). Jakarta: MUKISI.

Rahman MK, Zailani S and Musa G (2018). Tourists' satisfaction and loyalty intention at Shariah compliant private hos- pitals in Malaysia, International Journal of Tourism Sciences. Routledge, 18(4): 295-311.

Shariff SM and Mohtar S (2016). A Practical Journey in Implementing a Shari'ah Compliant Hospital: An Nur Specialist Hospital's Experience, 2nd World Congress on Islamisation and Integration of Human Knowledge, International Islamic University Malaysia, Kuantan, Malaysia.

Williams JA et al (2011). Attention to inpatients' religious and spiritual concerns: Predictors and association with patient satisfaction, Journal of General Internal Medicine, 26(11).

Zailani S et al. (2016). Predicting Muslim medical tourists' satisfaction with Malaysian Islamic friendly hospitals, Tourism Management, 57: 159-167.

Zakaria M (2014). The Influence of Human Needs in the Perspective of Maqasid alSyari'ah on Zakat Distribution Effectiveness, Asian Social Science, 10(3): 165.

Zatadini N and Syamsuri S (2018). Konsep Maqashid Syariah Menurut Al-Syatibi Dan Kontribusinya Dalam Kebijakan Fiskal, AL-FALAH (The Concept of Maqashid Syariah According to AlSyatibi and Its Contribution in Fiscal Policy, AL-FALAH ) : Journal of Islamic Economics, 3(2):1. 